assistance to other countries in the Middle East and South-East Asia which require the same assistance that has been given to Pakistan. Part 2 of the booklet deals with this scheme under the heading of "Training and Research Facilities", with sections on the climate, the buildings, seismology, geomagnetism, atmospheric physics, library, workshop and drawing offices, other facilities, Observatory publications, and general. The main emphasis of the Observatory is on practical work, and the standard is suitable for graduates in physics and mathematics, and also for geologists who have studied physics and have an aptitude for experimental physics. It is suggested that external students should stay at lezst six months and preferably nine to twelve months. Pakistan students are accepted for long-vacation courses, and, while instruments in regular use cannot be handled by them, they will receive facilities to learn all about their care, maintenance and adjustment. Short illustrated lectures are planned to guide students in practical activities, and visits to the Geological Survey, the chrome mines and the coalmining areas near Quetta will also be arranged.

\section{Bell Laboratories Record}

All those who are concerned with the science and practice of electrical communication should be interested in the Bell Laboratories Record, a well-produced and excellently illustrated monthly journal published by the Bell Telephone Laboratories, 463 West Street, New York 14. A perusal of recent issues shows that it deals with a wide variety of subjects ranging from the study of semi-conductors and the fundementel principles of television to the policy and technical problems involved in the planning and operation of a nation-wide telephone service. The December 1954 issue contains several features of interest to those concerned with some of the latest advances in radio techniques.

\section{Ratio of Iron to Manganese in Plants}

Continuing their studies on the mineral nutrition of plants, W. Leach and C. D. Taper have investigated the absorption of iron and manganese by various plant species grown in culture solutions (Canad. J. Bot., 32, No. 5, 561; 1954). Dwarf kidney beans and tomatoes were grown in complete nutrient solutions containing various concentrations of iron and manganese. The ratio of iron to manganese must be within a definite range in order to avoid deficiency symptoms in the experimental plants, namely, 1.5-3.0 for dwarf beans and $0 \cdot 5-5 \cdot 0$ for tomatoes. Concentration ratios outside the optimum range produced deficiency symptoms of one or other of these elements. Concentrations below minimum values of both elements always produced deficiency symptoms irrespective of the iron/manganese ratio in the culture solutions. An apparent antagonism between the absorption of iron and manganese was observed with both species, as also with onion. The combined amount of iron plus manganese absorbed appeared to remain constant irrespective of the ratio of iron to manganese in the culture solution.

\section{John Innes Horticultural Institution Leaflets}

OrIGLNally prepared to put the grower, the gardener and the seedsman into touch with the latest results of research, the well-known John Innes leaflets were first brought together in volume form in 1948 under the heading of "The Fruit, the Seed and the Soil". The publication was extremely suc- cessful, and, one year later, a new volume was issued containing all the original leaflets and three new ones. A third edition of the work has now been prepared in which substantial additions have been made to the leaflets dealing with growing tomatoes out of doors and sweet corn in England, while the leaflets concerned with composts, soil sterilization, raising plants in soil blocks, the fertility rules in fruit planting and making new plants by the colchicine method have been brought up to date.

\section{Chicago Natural History Museum}

ON behalf of the division of birds of the Chicago Natural History Museum, Austin L. Rand and Emmet R. Blake have prepared a delightful handbook illustrating the way the bird collections are set out. These are now arranged in habitat groups, the landscapes and the birds having been brought together from points as far apart as the Bering Sea and Antarctica; areas as widely scattered as Scotland, Chicago, Indo-China, the Kalahari Desert, New Zealand and Laysan Island are also represented. The specimens and accessory materials for the thirty-two habitat groups were either collected by museum expeditions or obtained through the generosity of friends of the Museum. A green peafowl exhibit was obtained as the result of a special expedition to French Indo-Chinz. The emperor penguins were captured by the Byrd Antarctic Expedition of 1935, while the white stork exhibit was the gift of the Polish American Chamber of Commerce, Warsaw. The book is illustrated by some fine colour and black-and-white photographs, linedrawings of distinction and a cover design of outstanding merit.

\section{International Pharmaceutical Federation}

THE sixteenth general assembly of the Féderation Internationale Pharmaceutique will be held in London during September 19-23, and is being organized by the Pharmaceutical Society of Great Britain. The opening and closing sessions and the science symposia will be held in Friends House, Euston Road, where a simultaneous translation service in English, French and German will be provided; the meetings of the sections will be in the Senate House, University of London. There will be four symposia, in which invited speekers will present papers, to be followed by general discussion; the subjects of the symposia will be : the pharmacy of blood, blood products and blood substitutes; recent advances in pharmaceutical analysis; ion exchange ; and tests for the sterility of pharmaceutical preparations. The secretary of the Organizing Committee is D. F. Lewis, Pharmaceutical Society, 17 Bloomsbury Square, London, W.C.1.

\section{Colonial Service: Recent Appointments}

THE following appointments have recently been made in the Colonial. Service: A. E. Billington (canning officer, Agricultural Department, Federation of Malaya), senior chemist, Agricultural Department, Federation of Malaya; E. R. H. Martin (agricultural officer, Antigua), agricultural officer, Jamaica; R. B. Reid (agricultural officer, Northern Rhodesia), chief agricultural officer, Northern Rhodesia; A. Jackson (chief chemist, Federation of Malaya), director of chemistry, Federation of Malaya; Tham Ah Kow (fisheries research officer, Singapore), fisheries officer, Singapore ; A. J. Browning (assistant conservator of forests, Sierra Leone), senior assistant conservator of 